\title{
Worker Absence and Shirking: Evidence from Matched Teacher-School Data
}

\author{
Steve Bradley, Colin Green; Gareth Leeves ${ }^{\ddagger}$
}

May 19, 2006

\begin{abstract}
We utilise a unique matched teacher-school data set of absenteeism records to quantify the impact of group interaction on the absence behaviour of primary and secondary teachers. To address problems of identification our study focuses on teachers who move between schools. The estimates for movers suggest that absenteeism is influenced by prevailing group absence behaviour at the school. Our findings suggest that a worker takes one more day of absenteeism if his average coworker takes 12 more days or 8 more days absenteeism per quarter for primary school and secondary school teachers, respectively. We interpret this as evidence that worker shirking is influenced by workplace absence norms.
\end{abstract}

KEYWORDS: Absenteeism, Shirking, Group Interaction Effects

JEL CODE: J29, J45, M54.

\footnotetext{
${ }^{*}$ Corresponding Author: Department of Economics, The Management School, Lancaster University, UK.

${ }^{\dagger}$ Centre for e-Science and Department of Economics, Lancaster University; Centre for Economic Policy Modelling, University of Queensland.

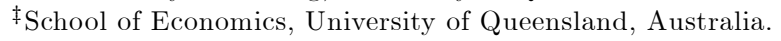




\section{Introduction}

Absenteeism is viewed as costly and disruptive for organisations. For instance, Barmby et al (2002) demonstrate for nine industrialised countries that a significant proportion of work hours are lost through absence, ranging from $1.8 \%$ to $6 \%$ of average weekly hours for Switzerland and Sweden, respectively. As we note later, figures for the teaching profession fall within this range. Teacher absence incurs direct costs through the organisation and payment of cover for absent teachers. In addition, there are indirect costs in terms of adverse effects on other staff and potentially on student performance (Ehrenberg et al 1986). In contrast, psychologists have suggested that absenteeism in stressful situations might be implicitly condoned by management because it is seen as a form of temporary relief for the employee, and could therefore be regarded as an efficient response (Steers and Rhodes 1978).

Devising an appropriate policy response to absenteeism is therefore complex, even more so when it is realised that worker absence can occur involuntarily because of physical or mental ill-health, or because of voluntary shirking behaviour by workers (Barmby et al 1994, Johansson and Palme 2002). A recent report by the Western Australian Government conjectures that up to $50 \%$ of absence amongst public sector workers, including teachers, is in fact voluntary, which implies a substantial degree of shirking (Auditor General 1997). ${ }^{1}$ Disentangling shirking behaviour (i.e. voluntary absence) from involuntary absence is

\footnotetext{
${ }^{1}$ Imants and van Zoelen (1995) suggested that only $20 \%$ of teacher absence could be directly related to what they described as justifiable medical grounds.
} 
extremely difficult to do in practice. Previous research has attempted to do so using absence spell length. However, as Driver and Watson (1989) argue this is unreliable because long spells of absence could be voluntary and a sequence of short spells could be indicative of recurring sickness.

Consequently, this paper does not explicitly try to distinguish between voluntary and involuntary absence. Instead, we take the approach of looking for peer, or group interaction, effects on individual absence behaviour, and also investigate the existence of multiple equilibria in this relationship. A significant positive association between individual and group behaviour in relation to absenteeism rates increases the likelihood that we are observing shirking behaviour rather than simply sickness. There are, however, serious identification problems when trying to establish whether group behaviour affects individual behaviour, which we discuss below, and to mitigate this problem our paper focuses attention on teachers who move between schools. In addition, we also assess the effects of endogeneity bias amongst movers by distinguishing between moves for promotion and other moves.

We use a unique and previously unused database of matched teachers and schools obtained from the Queensland government of Australia. Using this data we estimate cross-sectional and panel fixed effect models for the full sample as well as models for teachers who move schools. The results of cross-sectional models of absenteeism, though purely descriptive, are also reported to help fill the gap in the empirical literature on the correlates of absenteeism in the teaching profession and more generally within the public sector. The estimates 
for movers suggest that absenteeism is influenced by prevailing group absence behaviour at the school. Our findings suggest that a worker takes one more day of absenteeism if his average coworker takes 12 more days or 8 more days absenteeism per quarter for primary school and secondary school teachers, respectively. We are unable to find evidence of multiple equilibria, which at the simplest level would be reflected by a bimodal distribution of absence rates at the school level. Figure 1 shows that a bimodal distribution of absence rates is not observed for our population of schools, and we are unable to detect multiple equilibria in our statistical analysis. Teachers on temporary contracts have absenteeism rates $22 \%-24 \%$ lower than permanent teachers, which is consistent with earlier evidence on contract status effects in the private sector (Ichino and Riphahn 2005).

The rest of this paper is set out as follows. Section 2 contains a review of relevant literature, including a discussion of the notion of a sick school. Section 3 provides a detailed description of the data that are used in the empirical analysis. In section 4 we provide a theoretical framework and econometric methodology for the empirical work, which is followed by a discussion of the results in section 5. Section 6 concludes the paper.

\section{Literature Review}

A sizeable literature exists with regard to the influence of group interaction effects on a range of social and economic outcomes, such as crime, educational 
achievement, employment and ethnic skill differences (Case and Katz 1991, Borjas 1995, Glaeser et al 1996, Aaronson 1998, Sacerdote 2001, Marmaros and Sacerdote 2002, Arcidiacono and Nicholson 2005). Of particular relevance to the current study is Ichino and Maggi (2000) who found evidence of significant group interaction effects on individual shirking behaviour within a large Italian bank.

In the education literature, there have been many qualitative case studies of the factors influencing teacher absenteeism (Eisenberg et al 1986, Dworkin et al 1990, Imants and van Zoelen 1995), but little statistical analysis. Imants and van Zoelen (1995) argued that it was worthwhile classifying schools in terms of those that are healthy and those that are sick. Specifically, they found that collegial staff relationships and a supportive management style from the school principal reduced the rate of teacher absence. Furthermore, a recent report for Australia concluded that "motivation and commitment appear to be important elements which restrict absence through sickness", giving rise to a need for absent management programmes "that take account of the importance of schools' leaders in promoting healthy work environments" (Department of Education, Science and Training 2001).

The only previous econometric analysis of teacher absenteeism is Ehrenberg et al (1986), who focused on providing an explanation of the differences in average rates of teacher absenteeism between school districts because of differences in sick pay provisions. Average absenteeism was positively associated with the use of sick banks, whereby teachers accumulate unused sick leave, and negatively 
related to buy-back provisions that allowed unused sick leave to be cashed in. There was also some evidence to suggest that a larger fraction of teachers aged over 55 reduced sick leave usage. Of the variables controlling for school environment, the proportion of students living in an urban area and the ethnic composition of the student body were statistically insignificant but the average level of student absenteeism was positively correlated with teacher absenteeism, which implies that the effect of group behaviour on individual behaviour may extend beyond the influence of one's colleagues.

More generally, previous research on absenteeism conducted by economists has focused mainly on the private sector and investigated the impact of both individual (supply side) and workplace (demand side) characteristics (Delgado and Kniesner 1997, Barmby and Stephan 2000). Demand side factors that have been discussed in the literature include firm size (Coles and Treble 1996). It is shown that larger firms have higher rates of absenteeism, which arises because of their ability to diversify the risk from absence more easily (Barmby and Stephan 2000). Clearly, the same could apply in a school environment. Supply-side factors, such as age and gender, have been investigated using aggregate data by Paringer (1983) and Bridges and Mumford (2001). Both studies found that older and single workers were more likely to be absent, especially for men. However, Delgado and Kniesner (1997) found the opposite effects in a microeconomic study of London bus drivers.

The influence of the worker's contract status on absenteeism has also been investigated by Arai and Thoursie (2005) and others. For instance, Barmby et 
al (1995) and Barmby (2002) show that full time workers, or those with longer contracted hours, are more likely to be absent when compared to part time workers. Similarly, Ichino and Riphahn (2005) show that absence rates increase once a probationary period ends and employment protection legislation comes into effect.

\section{Data}

This study uses personnel records obtained from Education Queensland's human resource information system, and refer to the calendar and school years of 2001 and 2002 for all teachers employed in the state school system. The absenteeism data is recorded under a number of categories: family/paternity leave, work injury leave that is covered by employee insurance, time off due to industrial disputes, and absence due to reasons of self-reported illness. The absence days are recorded as the cumulative number of days per quarter. Our data tracks the individual teachers throughout the time period, thereby enabling us to construct a panel data set of teacher absenteeism. We focus on absence due to reported illness. Teachers can take up to two weeks sick leave per year. They can accumulate unused sick leave in a sick bank, which is transferrable between schools. There is no limit on how much leave can be accumulated, but unlike some school districts in the US, there are no buy-back provisions for unused sick leave.

In common with previous studies, we restrict our analysis to teachers who 
were employed throughout the two years, to remove possible bias related to the probationary teaching period and those teachers in the process of leaving the profession.

Table 1 shows summary statistics of teacher's absence. The figures are mean values for the percentage of working time lost and percentage of teachers taking absence. Figures for the UK from Bowers and McIver (2000) are presented for comparison. It is interesting that although full-time teachers in Australia are more likely to take absence, the average percentage of time lost through absence is similar in the UK and Australia.

For each teacher we have information on personal characteristics, such as age, gender, whether a worker has a disability, their length of tenure in the public sector and ethnic background; the latter is comprised of two groups, teachers from a Non-English Speaking Background (NESB) and other Australians. ${ }^{2}$ We also have data on the workplace characteristics of teachers, drawn from another source of school administrative data. From this we can determine the school the teacher was working at, and along with occupational codes allows us to distinguish between primary and secondary school teachers and the size of the school.

Queensland teachers can be employed under three types of contracts - casual, permanent or temporary. Casual teachers are generally short-term contract staff, usually 'relief' teachers, who may enter and leave the teaching workforce on a regular basis. Consequently, we exclude this group from our analysis. Tempo-

\footnotetext{
${ }^{2}$ Some teachers are indigenous Australians, however they represent a very small proportion of the teaching workforce and provide insufficient observations for statistical analysis.
} 
rary teachers are employed on fixed term contracts, generally of one years length, which can be renewed, whereas permanent teachers are in effect tenured. Additionally, teachers can be employed on a full-time or part-time basis. Unlike US school systems where there can be considerable variation in employment terms and conditions across school districts (Ehrenberg et al 1986), all Queensland teachers operate under the same basic pay and working conditions.

Measures of school quality are constructed from student record data that refer to all students in the Queensland state school system in 2001. For primary school students we have records for all year 7 students (the final year of primary school) and matching year 5 records (for 1999). For secondary students we have all year 10 student records (the final compulsory year of high school) and year 12 records for those pupils who remain in education. The student dataset also provides information on student test score performance. In our data we have test scores for year 7 (with matching year 5 scores) and standardized year 12 test scores. The individual pupil test scores are averaged for each school to provide an indicator of school quality. However, for secondary schools, year 12 test scores will not necessarily be an accurate representation of overall student quality. This is because: (a) poorer quality or less motivated students are likely to leave the school after the end of compulsory schooling (year 10); and (b) some students may choose to move to more successful schools to complete their high school. To allow for this our measure of secondary school quality utilises school retention data, which refers to the proportion of students who began at the school in year 7 and also completed at the same school in year 12 . 
Queensland covers a large area of land and geographically remote areas have higher concentrations of indigenous Australians who are, in educational and socio-economic terms, generally amongst the most disadvantaged individuals (Bradley et al 2005). Other schools are in regional centres and then there is the urban concentration of population in south east Queensland centred around Brisbane. As we have the postcode for each school, this enables us to identify urban, rural and remote schools.

In Table 2 we present summary statistics on variables used in the empirical analysis separately for primary and secondary schools. It is clear that women dominate primary school teaching by a ratio of 5 to 1 , whereas the gender disparity is much lower in secondary school teaching. Other covariates show little variation between primary and secondary schools. Three quarters of all secondary school teachers are non-specialists, the omitted case. ${ }^{3}$ Mean absenteeism rates are very similar for primary and secondary school teachers. Figure 2 displays the distribution of individual absence days. A large of proportion of teachers took less than 5 days absence over the 2 year period. At the same time, there is a clear tail at the right hand side of the distribution.

\footnotetext{
${ }^{3}$ The qualifications required to be a teacher in Australia differ between primary and secondary school sectors. Secondary school teachers generally complete an undergraduate course followed by a graduate diploma in education. Conversely, primary school teaching involves an undergraduate course dedicated to primary school education. As a result subject specialization and post-graduate study information is only available for secondary school teachers
} 


\section{Theoretical and econometric framework}

To analyse these data we draw upon the theoretical framework and econometric methodology developed by Ichino and Maggi (2000) in their study of absenteeism amongst the employees of an Italian bank. They suggest four broad determinants of individual variations in absenteeism. First, 'individual backgrounds', including personal characteristics, which in the present context also includes the contract status of the teacher. Second, the characteristics of the school in which the teacher works and the locality in which they live, for instance, the size of the school and the local unemployment rate, which are labelled 'locality' effects. These factors are what Manski (1995) refers to as contextual effects, and exogenous changes in them have no multiplied effect on teacher behaviour. Third, teachers may be sorted between schools which have different average absenteeism rates, which is linked to a fourth influence, that of group interaction. In this case, absenteeism of an individual teacher is influenced by the prevalence of that behaviour in the group (Manski 1993, Manski 1995), which gives rise to the idea of a social multiplier effect. Ichino and Maggi (2000) suggest that the social multiplier could arise in the shirking context via (i) a peer monitoring mechanism, that is, if more teachers shirk then an individual shirker is less likely to be reported thus the penalty is lower and hence shirking is higher; (ii) stigma effects, whereby shirking represents 'acceptable' behaviour; and (iii) if the school management has limited monitoring resources then the likelihood of being caught shirking is reduced.

In view of these considerations, it is suggested that workers will compare 
the benefits of shirking with the costs of shirking to maximise expected utility $(E U)$, as represented by Equation 1 .

$$
E U_{i t}=B\left(A_{i t}, S_{t}, \theta_{i}\right)-C\left(A_{i t}, \bar{A}_{t}\right)
$$

where $A_{i t}$ is the individual teacher's chosen level of absence in period $t, S_{t}$ is a set of school and locality factors, and $\theta_{i}$ represents the teacher's preference for absenteeism. $\overline{A_{t}}$ is the average absenteeism level of the school in period $t$, excluding the $i t h$ individual. ${ }^{4}$ The marginal penalty to absenteeism is lower for higher values of $\bar{A}_{t}$ for the reasons highlighted above. It follows that a teacher's propensity to absent themselves will be determined by the factors listed in Equation 2.

$$
A_{i t}=g\left(\bar{A}_{t}, S_{t}, \theta_{i}\right)
$$

From the assumptions above it follows that $\partial A_{i t} / \partial \bar{A}_{t} \geqslant 0$ and $\partial A_{i t} / \partial \theta_{i}>0$. Chatterji and Tilley (2002) introduce the concept of the 'presenter', these are workers with a low preference for absenteeism. Such workers derive satisfaction from being able to maintain a presence at work, regardless of illness, or see it is in their own best interest to carry out their duties. The teacher's concern for her class or the excess workload on colleagues, or perhaps their reputation with the school management, counterbalances the decrease in utility from illness or stress. Moreover, extra leisure time generates no increase in utility for this type of individual, and thus the presenter is likely to have a low value of $\theta$. We

\footnotetext{
${ }^{4}$ Throughout the empirical implementation $t$ refers to a quarter.
} 
cannot observe $\theta$ directly, however, it is likely that the preference for absenteeism is highly correlated with the personal characteristics of the teacher. Also, for workers on a temporary contract $C\left(A_{i t}\right)$ is likely to be higher as they face an increased likelihood of contract non-renewal if their absenteeism rate is judged to be unsatisfactory.

The first model that we estimate is therefore given by Equation 3. Initially, we ignore the time dimension in our data and simply estimate a cross-sectional model.

$$
A_{i}=\delta P_{i}+\beta \bar{A}+\gamma S+\epsilon
$$

$P_{i}$ is a vector of individual background characteristics. In a subsequent model we exploit the longitudinal nature of our data and redefine (3) as a panel data model with individual specific fixed effects:

$$
A_{i t}=\alpha_{i}+\delta t P_{i}+\beta \bar{A}_{t}+\sum_{d} \varsigma_{j} D_{j t}+\gamma S_{t}+\epsilon_{t}
$$

where $\alpha$ is an individual specific fixed effect, $D_{j t}$ is a dummy variable to capture unobserved locality effects where there are $d$ localities or districts. Ideally this variable would identify the school that a teacher was in at time $t$. However, as our focus is on teachers who move schools and the fact that there are insufficient teachers who movers to identify all 1123 school fixed effects, we therefore adopt a similar approach to Ichino and Maggi (2000) by including fixed effects for the 33 education districts. We argue that as education districts are reasonably homogenous with respect to pay and policies these should adequately 
capture the effect of time invariant local characteristics. Finally, $\delta t P_{i}$ is simply a time dummy interacted with ostensibly fixed individual background variables to control for time varying effects from observed individual characteristics.

There are two further issues that must be considered. First, because group interaction effects are endogenous, estimates of $\bar{A}_{t}$ may well be biased or even spurious. One source of endogeneity bias is the so-called 'reflection problem' whereby average group behaviour affects individual behaviour but each individual teacher's behaviour also affects average behaviour, which means that individual errors are correlated and hence our estimates will be biased. Another source of endogeneity bias arises if relevant school covariates are omitted, in which case the errors for teachers in the same school will be correlated and thus the effect of $\bar{A}_{t}$ will again be biased. Spurious effects arise where teachers behave in a similar way because they share a common set of unobservable characteristics which causes teachers to sort between schools.

In short, there is an identification problem, which we mitigate by investigating the effect of group interaction for the subset of teachers who move schools. ${ }^{5}$

Our model for movers is given by Equation 5:

$A_{i k t}-A_{i j t-1}=\beta\left(\bar{A}_{k t}-\bar{A}_{j t-1}\right)+\sum_{d}\left(D_{k t}-D_{j t-1}\right) \varsigma_{j}+\gamma\left(S_{k t}-S_{j t-1}\right)+\epsilon_{k t}-\epsilon_{j t-1}$

\footnotetext{
${ }^{5}$ Previous research has demonstrated that teachers move schools for both pecuniary and non-pecuniary reasons (Hanushek et al 2004, Bonesronning et al 2005).
} 
where $j$ refers to the origin school and $k$ the destination school; $D_{k t}-D_{j t-1}$ is an indicator that a teacher moved education district. The advantage of this approach is that we can explicitly control for individual fixed effects which is important if there is sorting of individuals with similar preferences for absence across the school system. ${ }^{6}$

Analysing only those teachers who move schools does not, however, solve the reflection problem completely. There still exists the possibility of several sources of bias, which are identified by Ichino and Maggi (2000). First, the stayers' mean shirking level may be endogenous because group interaction effects occur in the direction of mover to stayer. Second, $\bar{A}_{k t}-\bar{A}_{j_{t-1}}$ may also be biased due to unobserved locality effects which influence both mover and stayer behaviour. To try to remove the bias from these two sources we replace $\bar{A}_{k t}$ with its lagged value $\bar{A}_{k t-1}$ (referred to as test 1). Third, there still remains the possibility of measurement error, which downwardly biases our estimate of the group interaction effect. An alternative approach which may reduce all three sources of bias is to instrument $\bar{A}_{k t}$. We use $\bar{A}_{k t-1}$ as the instrument, on the assumption that this will directly affect stayers' current behaviour but not the mover's current behaviour (test 2). A further way of investigating the potential problems of endogenous stayer behaviour and the effect of unobservable local effects is to investigate whether the behaviour of the stayers is affected by the

\footnotetext{
${ }^{6}$ We checked whether there is seasonality in absence rates for teachers who move. There are variations in the timing of movement and of absence levels. More movement occurs at the end of the school year, however, omitting this quarter from our analysis has little effect on our results. Further absence levels do not appear to be seasonal in our data: the last quarter of the year, for instance, has both the highest absence rate (year 1) and the lowest absence rate (year 2).
} 
departure of bad workers (i.e. those with high absence rates) and the arrival of good workers (i.e. those with low absence rates). This involves regressing the change in the mean absence rate of stayers on a set of control variables, as well as the mean absence rate of newly arrived teachers, which is expected to have a positive effect, and the mean absence rate of those teachers who depart, which is expected to be negative. ${ }^{7}$ There still remains a potential bias, however, due to the endogeneity of the mean absence rates of arriving and departing teachers, which we seek to resolve by using the lagged mean absence rate of arriving teachers and the lead mean absence rate of departing teachers (test 3).

\section{Results}

Tables 3 and 4 report estimates of Equation 3 for primary teachers and secondary teachers, respectively. Our dependant variable is days absent during each quarter for each teacher. Initially we estimate Equation 3 by OLS. However, the record of teacher absenteeism in our data is a count of events, therefore estimation using a count data approach (Poisson model) is also used for comparison with the OLS estimates.

We report the incident rate ratio (IRR) for the Poisson model for ease of interpretation. Thus, an IRR greater than one indicates that the expected count in the exposed group is greater than the expected count in the unexposed group. For instance an IRR of 1.15 indicates a $15 \%$ increase in the absenteeism rate for

\footnotetext{
${ }^{7}$ This is equation 7 in Ichino and Maggi (2000).
} 
the exposed group, whilst 0.85 indicates a $15 \%$ decrease in the rate. Since there is a lack of detailed econometric evidence on the determinants of absenteeism amongst teachers, we first discuss the impact of individual background and locality factors before we move to the main focus of the paper, the estimation of group interaction effects. In these models we report estimates of the impact of school level absenteeism, however for the reasons noted above these estimates should be treated as descriptive.

\subsection{The effect of personal and locality characteristics on absenteeism}

The OLS results in Tables 3 and 4 show that there is a non-linear relationship between age and absenteeism which declines quite sharply for primary and secondary teachers but with slightly different turning points. For primary school teachers the turning point is around the age of 30 whereas for secondary school teachers it is age 28 , after which absenteeism increases. We also estimated a Poisson model where the age variable was grouped into bands to investigate the non-linear relationship in more detail. The findings (not reported) show that for primary and secondary school teachers there is a substantial increase in absenteeism for older age groups. For instance, secondary school teachers aged 31-40 have a $9 \%$ increase in absenteeism rates compared to younger teachers (30 years

or younger) whereas workers aged 61 or more have a $61 \%$ greater absenteeism rate, a differential of 52 percentage points. Similarly, the differential between primary school teachers aged $31-40$ and those aged 61 or more is 41 percent- 
age points. This is consistent with the age effects found in aggregate evidence (Bridges and Mumford 2001). These findings could be partly to do with the effect of taking accumulated leave before retirement (Ehrenberg et al 1986), or because of a gradual decline in enthusiasm for the job and hence an increase in absenteeism, given that we control for major health problems through the teacher being identified as disabled. There is no statistically significant gender difference in the incidence of absenteeism for either primary or secondary school teachers. Teachers from a Non English Speaking Background have absence rates that are between $8 \%$ and $11 \%$ higher. As expected, the impact of having a registered disability on the amount of absenteeism taken is very high, $31 \%$ and $25 \%$, respectively, for primary and secondary teachers.

There are some interesting findings with respect to contract status and the incidence of absenteeism. Workers on temporary contracts take significantly (22\%-24\%) fewer days of absence than their colleagues on permanent contracts, which may be indicative of a presenteeism effect in an attempt to secure a permanent contract (Ichino and Riphahn 2005). A further aspect of the contractual arrangement for teachers is that some are asked to perform higher duties in return for more pay. We find that those primary and secondary teachers undertaking such duties have around $20 \%$ to $24 \%$ less absence, which indicates that performance-related pay may reduce shirking. For secondary school teachers we note that absenteeism varies by subject specialism.

Turning to the locality effects, the effects of school size and the average quality of the pupil population are either statistically insignificant or very small. 
Some of the contextual effects are slightly larger and more significant, for instance, the higher the average age of the teaching body or the higher the proportion of teachers who are female in primary schools, the greater an individual teachers absence. We find that teachers in remote and rural schools take less absence than teachers in urban schools. This could be related to a greater commitment amongst teachers willing to take teaching posts in these localities, a wider sense of community involvement, or simply an inadequate supply of casual teachers, which means that teachers in non-urban areas are forced to present themselves for work to ensure that the class is taught. ${ }^{8}$

\subsection{The effect of group interaction on absenteeism}

Table 5 summarises our estimates of the group interaction effect that are derived from pooled OLS, panel and mover models. The dependent variable is the level or change in individual teacher absenteeism in each quarter over two years. Initially, we estimate pooled OLS models to provide estimates of group interaction effects without addressing the issues of unobserved heterogeneity and endogeneity. Column 2 presents estimates of $\beta$ obtained from a pooled OLS estimation of Equation 4 where the individual fixed effects term is dropped. The introduction of individual specific fixed effects (column 3) has no marked effect on the estimates. Indeed, these basic set of results suggest the presence of group interaction effects on absenteeism behaviour are not substantially changed by

\footnotetext{
${ }^{8}$ There is some support for this latter argument as casual teachers as a proportion of the total teacher workforce is much lower in remote areas; $50 \%$ less than in urban areas in the case of primary schools and $20 \%$ less for secondary schools
} 
the inclusion of controls for unobserved individual level heterogeneity.

A problem with these estimates, however, is that there is an identification problem for the reasons discussed earlier. We therefore estimate Equation 5 for those teachers who move schools, with and without the dummy variables, $D_{j t}$. In the appendix (Table A1) we present summary information on movers in comparison to stayers. The main differences are that movers are slightly younger, have a shorter tenure and are more likely to be on a temporary contract. Inter-school movement may be part of a sorting process where, for instance, teachers with higher absence propensities move to schools with higher average absence rates. However, it was found that individuals in the highest quartile of the absence distribution moved to schools that had a slightly lower average absenteeism than their origin school. For movers from other quartiles there was no discernible change in average school absenteeism between origin and destination. Hence, there does not appear to be systematic sorting across schools by absence propensity, at least within the 2 year time frame in which we observe movement. However, we investigate below if this is true for different types of movers.

Column 4 and 5 of Table 5 provide OLS estimates of the mover models. As these models are estimated for the period of movement, they provide estimates of the contemporaneous impact of group interaction effects on individual absenteeism. For primary school teachers the effect of $\bar{A}_{i k t}-\bar{A}_{i j t-1}$ is robust at around 0.07 , regardless of the inclusion of the district dummy variables, whereas for secondary school teachers the coefficient is between 0.10 and 0.12 . We can 
therefore claim that a worker takes one more day of absenteeism per quarter if his average coworker takes 12 more days or 8 more days absenteeism per quarter for primary school and secondary school teachers, respectively. The magnitude of these group interaction effects are lower for primary school teachers and similar for secondary teachers when compared to those previously reported for absenteeism in Ichino and Maggi (2000). Our results are also comparable to those found in other more general research on group interaction effects (see for instance Gaviria and Raphael (2001) and Falk and Ichino (2003)).

\subsection{Further tests}

Recall that our analysis of movers may not fully mitigate the identification problems referred to earlier. We therefore performed a series of tests, discussed above, to try to reduce the potential bias in our estimates of the group interaction effects. The results of test 1 lead to an increase in the magnitude of the group interaction effect to $0.110($ s.e. $=0.026)$ for primary school teachers and 0.234 (s.e. $=0.065)$ for secondary school teachers. These results suggest that our earlier estimates are downwardly biased, although the findings for secondary school teachers are higher than expected. The second test proved less conclusive insofar as the estimates were statistically insignificant, regardless of the choice of instruments. This is due to problems in finding suitable instrumental variables in our data. For the third test the estimated effect of the mean absence rate of arriving teachers is positive and that for departing teachers is negative, as expected, however, the estimates are small and statistically insignificant. This 
is not surprising as the number of movers is small relative to the number of stayers. It is likely, however, that the effect of group interaction is bigger in small schools simply because group norms are more easily and more directly transmitted. To test this hypothesis we re-estimated test 3 but for schools with less than 30 teachers, and the estimated effects are considerably larger, correctly signed but statistically insignificant. These findings are consistent with those of Ichino and Maggi (2000). ${ }^{9}$

Up to this point we have ignored the motivation for teachers to move school. This may impact upon our estimates of group interaction effects insofar as individuals whose absence behaviour is improving over time may move to lowabsence schools. If this occurs this would tend to overstate the relationship between individual and group absence behaviour and lead to an upwardly biased estimate of the effect of $\bar{A}_{i j t}-\bar{A}_{i k t-1}$ (Ichino and Maggi 2000). Our data does not explicitly identify reasons for movement between schools. However, we observe changes in a worker's job classification level and their wage rate, which means that we can identify those teachers who received a promotion as part of their school move and those who did not. Individuals who move as part of a promotion are more likely to have improving absence behaviour over time.

As a result we would expect estimates of group interaction effects to be more likely to be upwardly biased for promoted movers. We re-estimate our mover

\footnotetext{
${ }^{9}$ An additional issue is that reflection problems are likely to be particularly severe in workplaces with a smaller number of staff. To examine whether small schools were affecting the parameter estimates of our mover models, we re-estimated these models excluding movements to or from small schools (5 or less teachers). This was found to not materially alter our estimates of group interaction effects.
} 
model separately for the promoted and non-promoted sub-groups for primary and secondary school teachers, respectively. Estimates of $\bar{A}_{k t}-\bar{A}_{j t-1}$ for the non-promoted sub-group were approximately $0.064($ s.e. $=0.030)$ and 0.063 (s.e. $=0.059)$ for primary and secondary school teachers, respectively. The corresponding estimates for teachers who moved schools due to a promotion are $0.076($ s.e $=0.030)$ and $0.159($ s.e. $=0.068)$ for primary and secondary teachers, respectively. Similar to Ichino and Maggi (2000) we find that the estimates of group interaction effects for promoted workers are higher than those for other movers, and in the case of secondary school teachers these are statistically different. This suggests that the results in Table 5 may be slightly upwardly biased, especially in the case of secondary teachers. Nonetheless, for primary school teachers the estimates of group interaction effects are still statistically significant.

\section{Conclusion}

In this paper we have sought to analyse to what extent individual teacher absence behaviour is influenced by group behaviour. To do this we have used a unique database of all primary and secondary teachers employed in the Queensland public sector over a period of one year. To address problems related to the identification of group interaction effects we focused on those teachers who moved school during this period. Our results suggest that absenteeism is a function of observable teacher characteristics, such as disability, contract status and 
the remoteness of the school, however, group interaction effects also play a significant role in determining individual absenteeism. Our findings suggest that individual absenteeism will increase by one day if peer group absenteeism increase by between approximately 8 and 12 days. This is interpreted as evidence that worker shirking is influenced by workplace absence norms.

Overall, our results support previous research which demonstrates that individual absence behaviour is related to levels of absenteeism within the work unit (Ichino and Maggi 2000). This is particularly striking given that our data covers a system where work policies and procedures are highly standardised. Thus, although explicit differences in an organisation's policy can affect the level of absenteeism (Ehrenberg et al 1986), in this case variations in management and personnel factors at the school level seem a more likely explanation. It is also likely that the effect of group interaction reflects increased propensities to shirk at the individual teacher level. As a result, further research would do well to consider how absenteeism, and specifically the group-interaction effect, responds to human resource practices, such as changes in management staff and the manner in which absence management policies are applied. In summary, our results suggest that even in large bureaucratic organisations, such as state-based school systems, staff relationships and management style do affect the degree of teacher absence. 


\section{Acknowledgement}

The authors would like to thank Education Queensland for access to their data. The opinions expressed in this paper are those of the authors and do not necessarily represent the views of Education Queensland. The authors would like to thank Geraint Johnes and Rob Simmons for comments on a previous draft of this paper. We would also like to acknowledge the helpful comments of two referees and the Editor, which have improved the paper considerably.

\section{REFERENCES}

Aaronson, D. 1998 Using sibling data to estimate the impact of neighbourhoods on children's educational outcomes, Journal of Human Resources, 33, 915-946.

Arai, M. and Thoursie, P. S. 2005. Incentives and selection in cyclical absenteeism, Labour Economics, 12, 269-280.

Arcidiacono, P. and Nicholson, S. 2005 Peer effects in medical schools, Journal of Public Economics, 89, 327-350.

Auditor General. 1997. Get Better Soon: The Management of Sickness in the W.A. Public Sector. Office of the Auditor General, Perth.

Barmby, T. Ercolani, M. G. and Treble, J. G., 2002. Sickness Absence: An International Comparison. The Economic Journal 112, F315-F331.

Barmby, T. Sessions, J. and Treble, J. G., 1994. Absenteeism, Efficiency Wages and Shirking. Scandinavian Journal of Economics 94, 561-566. 
Barmby, T. Orme, C. D. and Treble, J. G., 1995. Worker Absence histories: a Panel Data Study. Labour Economics, 2, 53-65

Barmby, T. and Stephan, G., 2000. Worker Absenteeism: Why Firm Size May Matter. The Manchester School 68, 568-577.

Bonesronning, H., Falch, T. and Strom, B., 2005 Teacher Sorting, Teacher Quality and Student Composition. European Economic Review, 49, 457-483.

Borjas, G. 1995, Ethnicity, Neighbourhoods and Human-Capital Externalites. American Economic Review. 85, 365-390.

Bowers, T. and McIver, M., 2000. Ill Health Retirement and Absenteeism Amongst Teachers. Research Report RR235, DfES, UK. .

Bradley, S., Draca, M., Green, C. and Leeves, 2005. An Investigation of the Magnitude of Educational Disadvantage Amongst Indigeneous Minority groups in Australia, Forthcoming in Journal of Population Economics.

Bridges, S. and Mumford, K., 2001. Absenteeism in the UK: A Comparison Across Genders. The Manchester School 69, 276-284.

Case, A. C. and Katz, L. F., 1991. The Company You Keep: The Effects of Family and Neighbourhood on Disadvantaged Youths, NBER Working Paper No. 3705, Washington, USA.

Chatterji, M. and Tilley, C. J., 2002. Sickness, Absenteeism, Preseteeism and Sick Pay. Oxford Economic Papers 54, 669-687. 
Coles, M. G. and Treble, J., 1996. Calculating the Price of Worker Reliability. Labour Economics 3, 169-188.

Delgado, M. A. and Kniesner, T. J. 1997. Count Data Models with Variance of Unknown Form: An Application to a Hedonic model of Worker Absenteeism. The Review of Economics and Statisitics 79, 41-49.

Department of Education, Science and Training., 2001. Teachers in Australian Schools: A Report from the 1999 National Survey. Australian Government Publishing Service, Canberra.

Driver, R. W. and Watson, C., 1989. Construct Validity of Voluntary and Involuntary Absence. Journal of Business and Psychology 4, 109-118.

Dworkin, A. G., Haney, C. A., Dworkin, R. J. and Telschov, R. L., 1990. Stress and Illness Behaviour among Urban Public School Teachers. Educational Administration Quarterly 26, 60-72.

Ehrenberg, R.G., Ehrenberg, R.A., Rees, D. I. and Ehrenberg, E.L., 1989. School District Leave Policies, Teacher Absenteeism, and Student Absenteeism. Journal of Human Resources 26, 72-105.

Eisenberg, R., Huntington, R., Hutchinson, S. and Sowa, D., 1986. Perceived Organisational Support. Journal of Applied Psychology 71, 500-507.

Falk, A and Ichino, A. 2003 Clean Evidence on Peer Pressure. IZA Discussion Paper No. 732, Bonn. 
Gaviria, A. and Raphael, S. 2001 School-based Peer Effects and Juvenile Behaviour, Review of Economics and Statistics. 83, 257-268.

Glaeser, E.L., Sacerdote, B. and Scheinkman, J. A. 1996 Crime and Social Interactions, Quarterly Journal of Economics. May, 507-548.

Hanushek, E., Kain, J. and Rivkin, S., 2004.Why Public Schools Lose Students?, Journal of Human Resources. 39, 326-354.

Ichino, A. and Maggi, G. 2000 Work Environment and Individual Background: Explaining Regional Shirking Differentials in a Large Italian Firm. Quarterly Journal of Economics, August, 1057-1090.

Ichino, A. and Riphahn, R. T. 2005 The Effect of Employment Protection on Worker Effort: a Comparison of Worker Absenteeism During and After Probation. Journal of European Economic Association, 3, 120-143.

Imants, J. and van Zoelen, A., 1995. Teachers' Sickness Absence in Primary Schools, School Climate and Teachers' Sense of Efficiency. School Organization $15,77-87$.

Johansson, P. and Palme, M., 2002. Assessing the Effect of Public Policy on Worker Absenteeism. Journal of Human Resources 37, 381-409.

Manski, C., 1993 Identification of Endogenous Social Effects: The Reflection Problem. Review of Economic Studies, 60, 531-542.

Manski, C, 1995. Identification Problems in the Social Sciences. Harvard University Press, Cambridge. 
Marmaros, D. and Sacerdote, B., 2002. Peer and Social Networks in Job Search.

European Economic Review, 46, 870-879.

Paringer, L., 1983. Women and Absenteeism: Health or Economics. American Economic Review 73, 123-127.

Sacerdote, B., 2001 Peer Effects with Random Assignment: Results for Dartmouth Roommates. Quarterly Journal of Economics, 116, 681-704.

Steers, R. M. and Rhodes, S. R., 1978. Major Influences on Employee Attendance: A Process Model. Journal of Applied Psychology 63, 391-407. 
Figure 1: Distribution of Average Teachers Absent per School, 2001-2002. Source: Minimum Obligatory Human Resource Information (MOHRI)

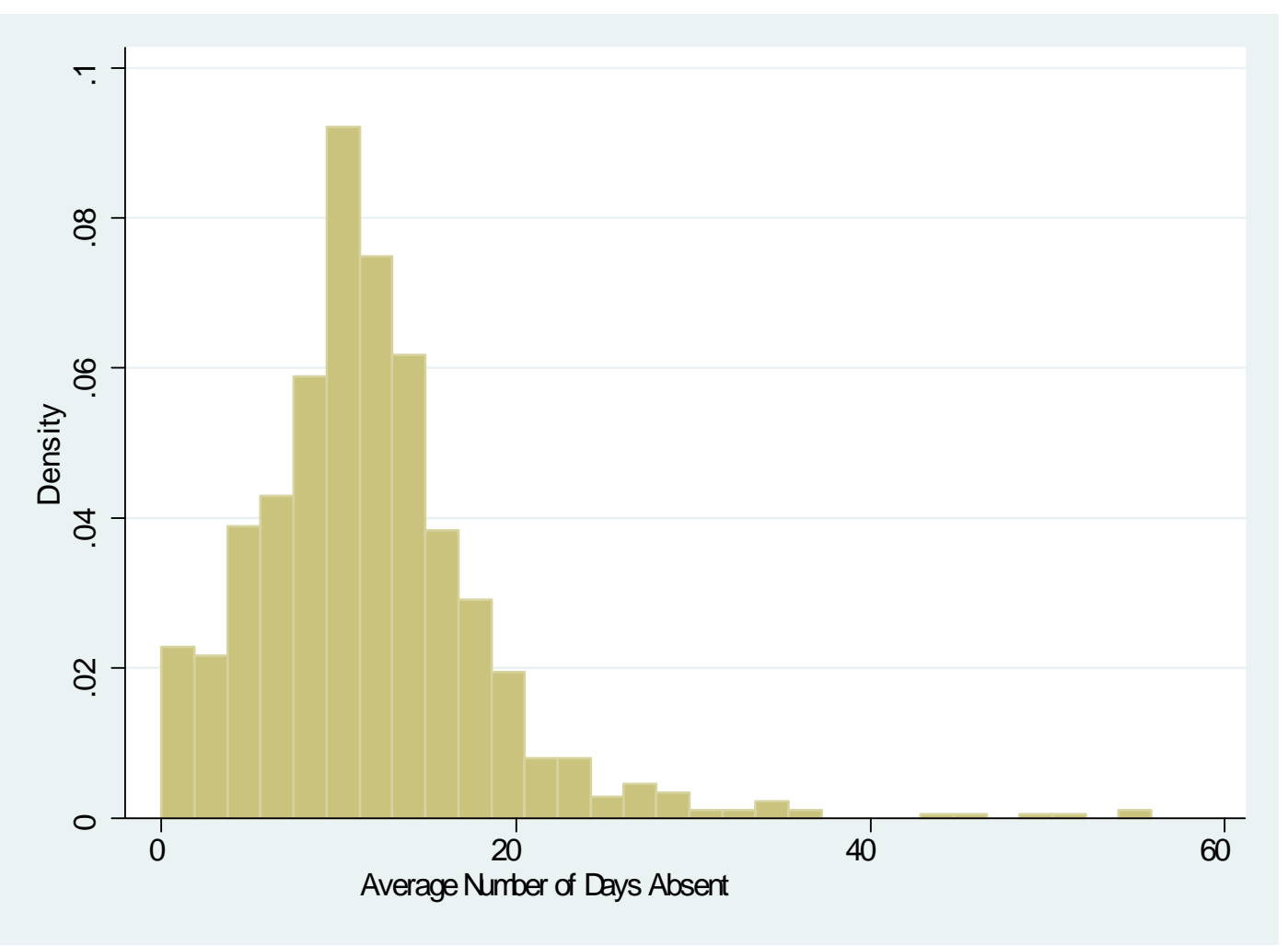


Figure 2: Distribution of Individual Teacher Absenteeism, 2001-2002. (Source MOHRI).

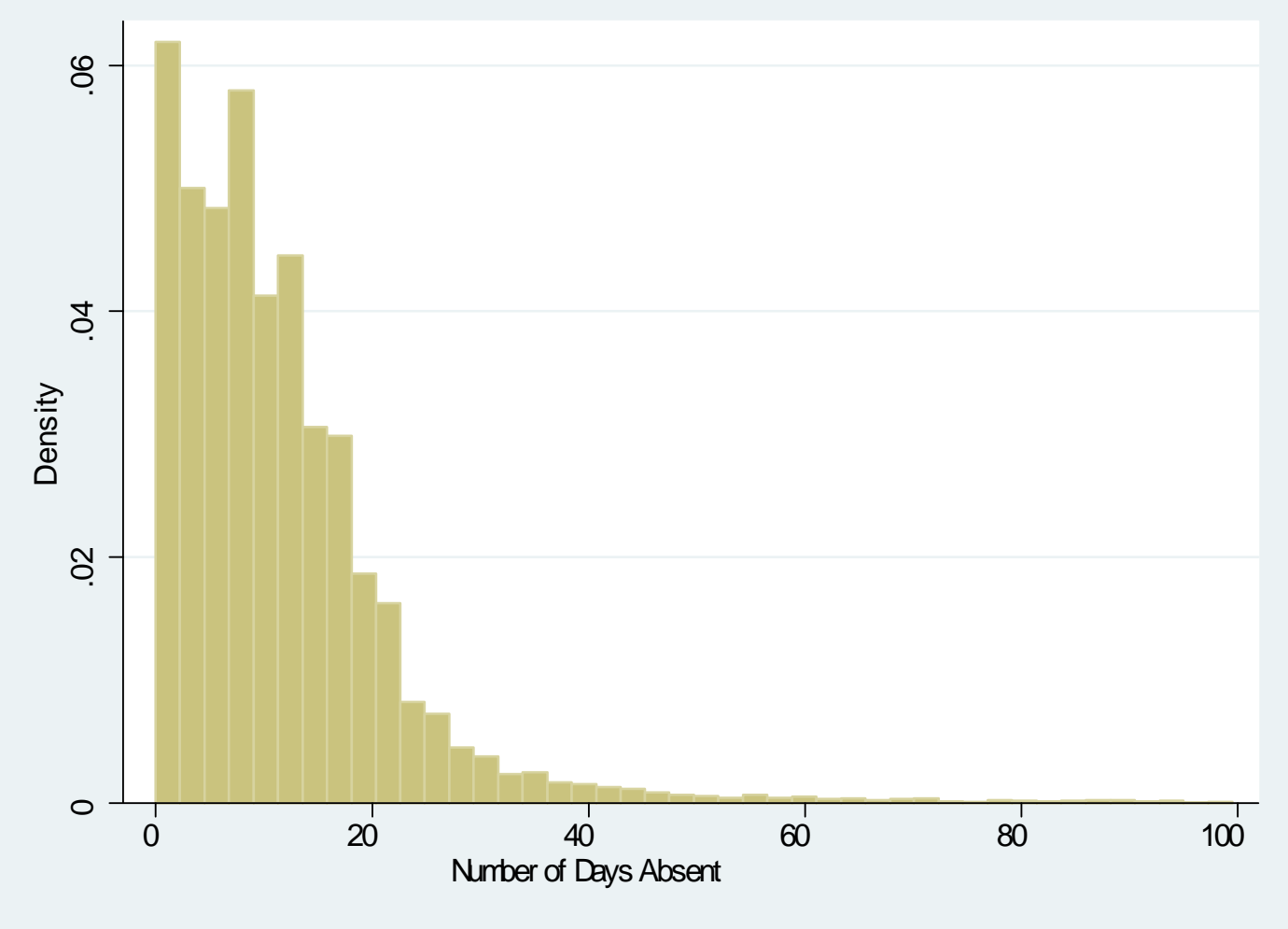


Table 1: Teacher Absence Rates, Australia and the UK

\begin{tabular}{|c|c|c|c|c|}
\hline & \multicolumn{3}{|c|}{ Australia 2002} & UK 1999 \\
\hline & Primary & Secondary & Overall & Overall \\
\hline Percentage time lost - All & 3.12 & 2.87 & & 3.15 \\
\hline Percentage time lost - Full-Time & 3.11 & 2.86 & & \\
\hline Percentage time lost - Part-Time & 3.12 & 2.87 & & \\
\hline Percentage taking absence - Full-Time & & & 86.65 & 65.19 \\
\hline Number of Teachers & & & 30,277 & 270,901 \\
\hline
\end{tabular}


Table 2: Summary Statistics, Queensland Teachers

\begin{tabular}{|c|c|c|c|c|}
\hline & \multicolumn{2}{|c|}{ Primary } & \multicolumn{2}{|c|}{ Secondary } \\
\hline & Mean & s.d. & Mean & s.d. \\
\hline Individual Absenteeism days per quarter & 1.50 & 1.96 & 1.44 & 2.05 \\
\hline Average School Level Absence per quarter\# & 1.52 & 0.77 & 1.49 & 0.50 \\
\hline Age (years) & 41.06 & 9.68 & 41.61 & 9.71 \\
\hline Tenure (years) & 12.26 & 10.22 & 12.65 & 10.00 \\
\hline Male & 0.18 & 0.38 & 0.40 & 0.49 \\
\hline Non English Speaking Background & 0.06 & 0.24 & 0.08 & 0.27 \\
\hline Disability & 0.06 & 0.23 & 0.07 & 0.25 \\
\hline Temporary Contract & 0.04 & 0.21 & 0.03 & 0.16 \\
\hline Part Time & 0.15 & 0.36 & 0.07 & 0.25 \\
\hline Higher Duties & 0.02 & 0.12 & 0.06 & 0.23 \\
\hline \multicolumn{5}{|l|}{ School Characteristics } \\
\hline Proportion of Teachers Female & 0.82 & 0.09 & 0.60 & 0.06 \\
\hline Average Age & 40.95 & 3.77 & 41.58 & 2.66 \\
\hline Average Tenure (years) & 11.90 & 3.70 & 12.33 & 2.72 \\
\hline Local Area Unemployment Rate & 8.58 & 4.02 & 8.93 & 4.24 \\
\hline Rural School & 0.21 & 0.41 & 0.17 & 0.357 \\
\hline Remote School & 0.09 & 0.29 & 0.06 & 0.24 \\
\hline Average Literacy Score (year 7) & 681.94 & 35.23 & & \\
\hline Retention Rate & & & 76.93 & 17.25 \\
\hline Science & & & 0.12 & 0.33 \\
\hline Humanities & & & 0.14 & 0.34 \\
\hline Number of Observations & 15,849 & & 9,655 & \\
\hline
\end{tabular}

Source: MOHRI. ${ }^{\#}$ Excludes the absenteeism level of the $i t h$ individual. 
Table 3: The Determinants of Absenteeism Amongst Primary School Teachers (Dependant Variable is Days Absent per Quarter)

\begin{tabular}{|c|c|c|}
\hline & $\begin{array}{l}\text { OLS } \\
\text { Coeff }\end{array}$ & $\begin{array}{l}\text { Poisson } \\
\text { IRR }\end{array}$ \\
\hline \multirow[t]{2}{*}{$\bar{A}$} & $0.103^{*}$ & $1.061^{*}$ \\
\hline & $(0.013)$ & $(0.007)$ \\
\hline \multirow[t]{2}{*}{ Age (years) } & $-0.042^{*}$ & $0.982^{*}$ \\
\hline & $(0.010)$ & $(0.006)$ \\
\hline \multirow{2}{*}{$\mathrm{Age}^{2}$} & $0.001 *$ & $1.0003^{*}$ \\
\hline & $(0.0003)$ & $(0.0001)$ \\
\hline \multirow[t]{2}{*}{ Tenure (years) } & $0.006 *$ & $1.003^{*}$ \\
\hline & $(0.002)$ & $(0.001)$ \\
\hline \multirow[t]{2}{*}{ Male } & -0.002 & 1.001 \\
\hline & $(0.030)$ & $(0.186)$ \\
\hline \multirow[t]{2}{*}{ Non English Speaking Background } & $0.133^{* *}$ & $1.083^{* *}$ \\
\hline & $(0.053)$ & $(0.034)$ \\
\hline \multirow{2}{*}{ Disability } & $0.480 *$ & $1.307^{*}$ \\
\hline & $(0.064)$ & $(0.041)$ \\
\hline \multirow{2}{*}{ Temporary Contract } & $-0.315^{*}$ & $0.781^{*}$ \\
\hline & $(0.033)$ & $(0.023)$ \\
\hline \multirow[t]{2}{*}{ Part Time } & $-0.698^{*}$ & $0.544^{*}$ \\
\hline & $(0.024)$ & $(0.137)$ \\
\hline \multirow[t]{2}{*}{ Higher Duties } & $-0.306^{*}$ & $0.804^{*}$ \\
\hline & $(0.089)$ & $(0.056)$ \\
\hline \multirow[t]{2}{*}{ Average Literacy year $7 / 100$} & 0.025 & 1.014 \\
\hline & $(0.034)$ & $(0.024)$ \\
\hline \multirow[t]{2}{*}{ School Enrolment/100 } & 0.010 & $1.008^{* *} *$ \\
\hline & 0.006 & $(0.003)$ \\
\hline \multirow[t]{2}{*}{ Proportion Teachers Female } & $0.239^{* *}$ & 1.177 \\
\hline & $(0.115)$ & $(0.098)$ \\
\hline \multirow[t]{2}{*}{ Average Age } & $0.010 * *$ & 1.007 \\
\hline & 0.005 & $(0.004)$ \\
\hline \multirow{2}{*}{ Average Tenure (years) } & -0.003 & 0.999 \\
\hline & 0.005 & $(0.004)$ \\
\hline \multirow[t]{2}{*}{ Rural School } & $-0.092^{*}$ & $0.938^{*}$ \\
\hline & $(0.029)$ & $(0.019)$ \\
\hline \multirow[t]{2}{*}{ Remote School } & $-0.157^{*}$ & $0.885^{*}$ \\
\hline & $(0.046)$ & $(0.033)$ \\
\hline \multirow[t]{2}{*}{ Local Unemployment Rate } & 0.006 & $1.004^{*}$ \\
\hline & $(0.003)$ & $(0.002)$ \\
\hline Constant & 1.53 & \\
\hline Number of Observations & 126792 & 126792 \\
\hline $\mathrm{r}^{2} /$ pseudo $^{2}$ & 0.04 & 0.11 \\
\hline Wald $\operatorname{chi}^{2}(25)$ & & 5029.83 \\
\hline Log Likelihood & & -257301.36 \\
\hline
\end{tabular}


Table 4: The Determinants of Absenteeism Amongst Secondary School Teachers (Dependant Variable is Days Absent per Quarter)

\begin{tabular}{|c|c|c|}
\hline & $\begin{array}{l}\text { OLS } \\
\text { Coeff }\end{array}$ & $\begin{array}{l}\text { Poisson } \\
\text { IRR }\end{array}$ \\
\hline$\overline{\bar{A}}$ & $\begin{array}{l}0.164^{*} \\
(0.023)\end{array}$ & $\begin{array}{l}1.109^{*} \\
(0.015)\end{array}$ \\
\hline Age (years) & $\begin{array}{l}-0.032^{* *} \\
(0.014)\end{array}$ & $\begin{array}{l}0.986 \\
(0.009)\end{array}$ \\
\hline $\operatorname{Age}^{2}$ & $\begin{array}{l}0.001^{*} \\
(0.0002)\end{array}$ & $\begin{array}{l}1.0003 \\
(0.0001)\end{array}$ \\
\hline Tenure (years) & $\begin{array}{l}0.002 \\
(0.002)\end{array}$ & $\begin{array}{l}1.001 \\
(0.001)\end{array}$ \\
\hline Male & $\begin{array}{l}-0.064^{* *} \\
(0.029)\end{array}$ & $\begin{array}{l}0.955 * * \\
(0.020)\end{array}$ \\
\hline Non English Speaking Background & $\begin{array}{l}0.158^{*} \\
(0.056)\end{array}$ & $\begin{array}{l}1.110^{*} \\
(0.039)\end{array}$ \\
\hline Disability & $\begin{array}{l}0.361^{*} \\
(0.073)\end{array}$ & $\begin{array}{l}1.246^{*} \\
(0.051)\end{array}$ \\
\hline Temporary Contract & $\begin{array}{c}-0.352^{*} \\
(0.069)\end{array}$ & $\begin{array}{l}0.756^{*} \\
(0.046)\end{array}$ \\
\hline Part Time & $\begin{array}{l}-0.581^{*} \\
(0.050)\end{array}$ & $\begin{array}{l}0.582^{*} \\
(0.033)\end{array}$ \\
\hline Higher Duties & $\begin{array}{c}-0.339^{*} \\
(0.046)\end{array}$ & $\begin{array}{l}0.762^{*} \\
(0.031)\end{array}$ \\
\hline Retention Rate/10 & $\begin{array}{l}0.003 \\
(0.096)\end{array}$ & $\begin{array}{l}1.002 \\
(0.006)\end{array}$ \\
\hline School Enrolment/100 & $\begin{array}{l}0.005 \\
(0.004)\end{array}$ & $\begin{array}{l}1.004 \\
(0.003)\end{array}$ \\
\hline Proportion Teachers Female & $\begin{array}{l}-0.414 \\
(0.254)\end{array}$ & $\begin{array}{l}0.725 \\
(0.133)\end{array}$ \\
\hline Average Age & $\begin{array}{l}0.011 \\
(0.012)\end{array}$ & $\begin{array}{l}1.009 \\
(0.009)\end{array}$ \\
\hline Average Tenure (years) & $\begin{array}{l}-0.013 \\
(0.011)\end{array}$ & $\begin{array}{l}0.990 \\
(0.008)\end{array}$ \\
\hline Rural School & $\begin{array}{l}-0.121^{* *} \\
(0.050)\end{array}$ & $\begin{array}{l}0.909 * * \\
(0.036)\end{array}$ \\
\hline Remote School & $\begin{array}{l}-0.118 \\
(0.087)\end{array}$ & $\begin{array}{l}0.899 \\
(0.068)\end{array}$ \\
\hline Local Unemployment Rate & $\begin{array}{l}0.007 \\
(0.004)\end{array}$ & $\begin{array}{l}1.005 \\
(0.003)\end{array}$ \\
\hline Science & $\begin{array}{l}-0.118^{*} \\
(0.036)\end{array}$ & $\begin{array}{l}0.915^{*} \\
(0.025)\end{array}$ \\
\hline Humanities & $\begin{array}{l}-0.015 \\
(0.043)\end{array}$ & $\begin{array}{l}0.990 \\
(0.031)\end{array}$ \\
\hline Constant & 1.75 & \\
\hline Number of Observations & 77240 & 77240 \\
\hline $\mathrm{r}^{2} /$ pseudo $\mathrm{r}^{2}$ & 0.02 & 0.07 \\
\hline $\begin{array}{l}\text { Wald chi }{ }^{2}(27) \\
\text { Log Likelihood }\end{array}$ & & $\begin{array}{l}2746.92 \\
-158001.20\end{array}$ \\
\hline
\end{tabular}


Table 5: Estimates of Group Interaction Effects (Dependent Variable is Days Absent per Quarter)

\begin{tabular}{lllll}
\hline & Pooled & Panel & & \multicolumn{2}{c}{ Movers } \\
& OLS & Fixed Effects & with District Controls & without District Controls \\
\hline Primary & $0.102^{*}$ & $0.108^{*}$ & $0.069^{*}$ & $0.069^{*}$ \\
Secondary & $(0.013)$ & $(0.015)$ & $(0.022)$ & $(0.021)$ \\
& $0.164^{*}$ & $0.123^{*}$ & $0.122^{* *}$ & $0.104^{* *}$ \\
& $(0.023)$ & $(0.024)$ & $(0.052)$ & $(0.048)$ \\
\hline Robust standard errors in parentheses clustered at the individual level in the pooled \\
models, at the school level for panel and mover models.Controls for pooled OLS as \\
per Table 3 \& 4. Panel Fixed Effects Models include time varying individual specific \\
characteristics $\left(\delta t P_{i}\right)$. Mover models include differences $(t-t-1)$ in time varying \\
characteristics.
\end{tabular}


Table A1 Comparision of Movers and Stayers

\begin{tabular}{lclll}
\hline & \multicolumn{2}{c}{ Movers } & \multicolumn{2}{c}{ Stayers } \\
& Mean & s.d. & Mean & s.d. \\
\hline Individual absence over 2 years & 11.55 & 11.67 & 11.75 & 11.09 \\
Age & 38.45 & 9.80 & 41.71 & 9.75 \\
Tenure (years) & 8.07 & 8.35 & 12.78 & 10.37 \\
Male & 0.25 & 0.43 & 0.27 & 0.44 \\
Non-English speaking background & 0.06 & 0.23 & 0.07 & 0.25 \\
Disability & 0.05 & 0.22 & 0.06 & 0.24 \\
Temporary contract & 0.12 & 0.32 & 0.05 & 0.21 \\
Part-time contract & 0.13 & 0.34 & 0.11 & 0.32 \\
Higher duties & 0.02 & 0.13 & 0.01 & 0.10 \\
Primary Teacher & 0.69 & 0.46 & 0.61 & 0.49 \\
Promotion & 0.26 & 0.44 & 0.25 & 0.43 \\
School Characteristics & & & & \\
Average age at school & 40.58 & 4.42 & 41.38 & 3.42 \\
Average tenure at school (years) & 11.35 & 4.19 & 12.27 & 3.59 \\
Rural school & 0.23 & 0.42 & 0.19 & 0.39 \\
Remote school & 0.14 & 0.34 & 0.08 & 0.27 \\
Local unemployment rate & 8.77 & 4.36 & 8.72 & 4.11 \\
Observations & 4,817 & & 20,617 & \\
\hline
\end{tabular}

